\title{
Substancialidade A'uwê no espelho Waradzu: escutar o corpo indígena Xavante em contexto de trânsito espacial e cultural
}

\author{
A'uwê substanciality on Waradzu mirror: listening to \\ indigenous Xavante's body within a spatial and cultural \\ exchange context
}

\author{
Maria Clara Campos ${ }^{1}$ \\ José Francisco Miguel Henriques Bairrão ${ }^{1}$
}

DOI: http://dx.doi.org/10.20435/tellus.v0i42.689

Resumo: Para os Xavante, um melhor entendimento do mundo dos brancos e a capacidade de trazer melhorias para seu povo mediante estadias fora de seu território é habilidade crucial na competência de um líder. Em meados do século XX, o cacique Apöena, da Terra Indígena de Pimentel Barbosa, estabeleceu vínculos com um grupo de brancos de Ribeirão Preto, SP, e determinou a migração de oito de seus netos, todos do sexo masculino, para a cidade de origem do grupo. O presente artigo tem como enfoque a história de alguns protagonistas atuais desse intercâmbio. Objetivou-se perscrutar, mediante inclusive a sua expressão em práticas corporais, as suas perspectivas de si e de futuro e os seus efeitos na construção e transformação identitária. Para esse efeito, foram realizadas análises de entrevistas não estruturadas, realizadas com os jovens e suas famílias brancas, sob o enfoque metodológico da etnopsicanálise. Elucidou-se que esse encontro engendrou formas ativas e singulares de construção identitária e de ressignificação da tradição e memória Xavante por parte desses jovens, tanto no atinente às suas respectivas biografias quanto no entendimento dessas como uma forma de resposta à missão que Ihes foi confiada pelo seu povo. Evidencia-se, nessa perspectiva, a importância de se ultrapassar concepções atidas à aculturação de indivíduos indígenas em contato com o meio urbano, levando em conta suas sociocosmologias particulares.

Palavras-chave: etnopsicologia; etnopsicanálise; povos indígenas; Xavante; corporalidade 


\begin{abstract}
A better understanding of the white man's world and the ability to improve the natives' lifes are crucial skills for a Xavante leader. During the mid-20th century, Pimentel Barbosa's Indigenous Land Chief Apöena established bonds with a group of white men from Ribeirão Preto, SP, and ordered the migration of eight of his male grandchildren to the countryside city. This study focuses on the story of a few of the current protagonists of this cultural exchange. Their perspectives on self, future and its effects on identity construction and transformation were probed, including the manifestation of these elements in corporal practices. To achieve this objective, we conducted non-structured interviews with the young indigenous men and their host white families, which were later analyzed under the ethnopsychanalysis methodological framework. It became clear that this cultural exchange resulted in active and singular ways of identitary construction and meaning construction about Xavante memory and tradition for these young men, in what it relates to their biographies, and the understanding of them as a way to respond to the mission that was bestowed on them by their people. In this perspective, it becomes evident the importance of going beyond conceptions of acculturation of indigenous individuals in contact with the urban setting, and the necessity to take into account their particular sociocosmologies.
\end{abstract}

Keywords: ethnopsychology; ethnopsychanalysis; indigenous people; Xavante; corporeality

\title{
1 INTRODUÇÃO
}

Na contramão do quase consenso de que os povos indígenas não possuíram meios de defesa diante das investidas dos brancos - seja na guerra, seja na resistência biológica, na conversão religiosa ou na esfera política -, o povo Xavante (os $a^{\prime} u w e ̂$ ) desenvolveu diversas estratégias de relacionamento com os não índios (os waradzu), a fim de favorecer a sua sobrevivência. É possível observar, com efeito, diversos processos desenvolvidos por essa etnia direcionados a um aprendizado das sistematizações do mundo do branco e toda a sua inerente complexidade. Por meio desses procedimentos, os Xavante buscam, entre outros aspectos, retomar e fortalecer suas capacidades de ação, bem como reverter o quadro pessimista para sua população - determinado por perdas territoriais e demográficas ocasionadas nos primeiros anos de contato com os não nativos (GORDON, 2014).

A obtenção de conquistas para esse povo se deu, ademais, pela extrema habilidade com a qual administrou as relações que foi estabelecendo com o branco. Tal competência se embasa, entre outras razões, na organização social dualista inerente ao sistema Xavante, marcada por divisões em metades opostas, contrastivas 
e complementares - característica comum aos demais povos Jê. A fragmentação de toda a sociedade em duas metades clânicas que, ao mesmo tempo em que se contrapõem, consolidam alianças entre si (sobretudo matrimoniais) beneficia a coesão interna do grupo por meio de uma lógica em que se "divide para somar", em que o nós não existe sem o outro, este que vem a complementar e agregar. Por essa razão, os Xavante aparentam dominar mais facilmente o jogo sutil e arriscado das relações mutuamente constitutivas entre eu e outro, de forma a manter os "antagonismos em equilíbrio" (GORDON, 2014; SOARES, 2008).

Baseando-se nessas propensões, somadas ao crescimento de seu contato com os waradzu, os Xavante engendraram processos migratórios para centros urbanos, especificamente para cidades localizadas nos estados do Rio de Janeiro, São Paulo, Paraná, Minas Gerais e, sobremaneira, Goiás. A capacidade de obter melhoramentos por meio dos deslocamentos fora da aldeia tornou-se, assim, qualidade imprescindível na determinação da competência de um líder (TORAL, 1986).

Por esse prisma, o cacique Apöena, da Terra Indígena de Pimentel Barbosa, estabeleceu contato e vinculação com um grupo de brancos de Ribeirão Preto, SP, em visita às aldeias, ao fim da década de 1950 e início da conseguinte. Alicerçado nessa proximidade, o líder indígena determinou a migração de oito de seus netos, todos do sexo masculino, para a cidade de origem do grupo, com o objetivo de os jovens aprenderem a língua e a cultura do waradzu sob tutela de famílias não índias, as quais, em comum acordo, se dispuseram a zelar pelas crianças e thes fornecer a educação formal do branco (ESTRATÉGIA..., 2006).

O fenômeno engendrado pelo antigo cacique tem sua continuação na contemporaneidade. Alguns jovens Xavante atualmente trilham caminhos semelhantes aos de seus ascendentes, residindo hodiernamente na cidade de Ribeirão Preto com o intuito de viver e de se socializar no mundo branco, imersos em famílias não indígenas. Entre diversas consequências individuais e coletivas, a experiência de trânsito vivenciada ocasiona aos jovens indígenas efeitos sobre seus processos de construção identitária, sobretudo em função da dinamicidade que se opera na simbolização e síntese dos dois universos em que passam a cursar. O trânsito entre dois universos culturalmente e espacialmente distintos impacta, nesse sentido, a elaboração da autoimagem desses jovens, tal como as suas perspectivas de futuro e formas de ação. 
Caiuby Novaes (1993), ao utilizar-se do recurso metafórico do "jogo de espeIhos", permite uma análise dinâmica desse fenômeno da construção da identidade. Segundo essa, ao focalizar um segmento populacional, um grupo simultaneamente constitui uma imagem de si próprio, a partir de sua percepção aos olhos desse outro segmento. O outro, deste modo, torna-se uma espécie de espelho, em que a cada imagem refletida simetriza-se uma possibilidade de atuação, sendo essa corroborativa da imagem ou buscando corrigi-la. O prisma de visão dos grupos uns sobre os outros não implica uma visão unívoca, mas uma mescla de óticas e interpretações que se refletem e interpõem, gerando, assim, um caleidoscópio de imagens e posicionamentos possíveis, resultados dessa interação.

Semelhante noção é abordada pela psicanálise lacaniana por meio do Estádio do Espelho, salientando a importância fundamental do outro na imagem assumida pelo sujeito desde os primórdios da vida, tendo a identificação com essa imagem implicações diretas nesse último (CUKIERT; PRISZKULNIK, 2002; LACAN, 1998). Marcado pelo desconhecimento e a alienação, a imagem do eu constrói-se, desse modo, a partir da imagem devolvida por seu semelhante, constituindo uma fusão do desejo do sujeito alienado ao desejo do outro (CUKIERT; PRISZKULNIK, 2002). Os jovens abordados, direcionando-se a diferentes famílias, essas com formas dissemelhantes de relacionar-se com o quadro que se constrói a partir do acordo selado entre os povos, têm diante de si "espelhos-outros" de diferentes configurações. Logo, apreenderão dissemelhantes imagens de si e distintas formas de atuação a partir dessas. Tais disparidades, por sua vez, presumivelmente devem ocasionar reconfigurações, eventualmente ampliações ou supressões, no modo pelo qual esses passam a significar e apropriar-se das marcas identitárias corporais Xavante e expressar suas próprias corporalidades.

Conforme Müller (1976), a ornamentação corporal indígena corresponde a uma linguagem simbólica referente à ordem social, outorgando um modelo de como a sociedade em questão é idealmente estruturada por aqueles pertencentes a ela. Entre os Xavante, relaciona-se à divisão da sociedade em grupos sociais, a diferentes status e à passagem por esses. Não concerne, desse modo, a mera ilustração visual, mas é um sistema detentor de estrutura lógica particular, consonante a outras estruturas da sociedade em questão, referentes a grupos de idade, de parentesco e atuações ritualísticas, por exemplo. 
A expressão de certos aspectos da corporalidade Xavante, tal como as experiências suscitadas por esses usos e modelações do corpo, nessa perspectiva, configura-se substancial na construção e socialização dos sujeitos enquanto constituintes da coletividade e em suas subjetividades. Nessa direção, ultrapassa-se o sentido individualizante do corpo, passando a uma abordagem desse como componente social que atua, identifica-se e produz disparidades na relação com outros corpos, considerando os tipos de interação em questão (SPAOLONSE, 2006). Citando diretamente o autor:

Por um lado, pode se dizer que o corpo é modelado socialmente conforme os papéis assumidos ao longo da vida, e por outro, que a experiência desta modelação corporal, dotada de um valor social específico, transforma não somente o corpo, mas o próprio entendimento que se tem dele e do papel social assumido através de sua modelação. A experiência é marcada na pele e na carne, e o valor atribuído a ela pelo coletivo funde-se às próprias expectativas e sensações vivenciadas. (SPAOLONSE, 2006, p. 51-2).

Para além das concepções consuetudinárias em contexto tradicional Xavante, Borges (2013) propõe reflexionar o corpo do sujeito Xavante entremeado ao da cidade, constituindo materialidades discursivas que se amalgamam, enredam-se. Aludindo à noção defendida por Orlandi (2004) de que em espaços distintos pronunciam-se diferentes permissividades a determinados tipos de corpos, abrigando-os ou excluindo-os, e, dessarte, posicionam-se os sujeitos dentro desse meio de modo singular, a autora afirma haver uma interconstitutividade entre espaço e corpo na identificação do sujeito em seu discurso. O corpo pode ser visto, dessa forma, como materialidade significante que posiciona os sujeitos em determinados locais de fala, sendo o primeiro desses materiais simbólicos a abrir-se à significação para o outro, considerando o discurso no âmbito do visual, na relação entre sujeitos (HASHIGUTI, 2007).

Dessa forma, discorrer sobre o corpo sob o prisma simbólico é ultrapassá-lo do âmbito do imaginário, da formação do eu e da imagem, como exposto brevemente anteriormente. Concretiza-se o corpo como lugar primeiro do Outro, coincidindo-o com a borda em que os significantes, elementos topologicamente apreensíveis dessa estrutura, inscrevem-se (BAIRRÃO, 2003), compondo esse mesmo corpo e dialogando entre si (NASIO, 1993). É nessa perspectiva que, enquanto corpo, sucede-se o sujeito da enunciação. É o corpo que se faz objeto, mas 
é primordialmente sujeito, "sensível ao sopro de outros corpos, 'materialmente' sujeitado pelo simbólico e pulsar continente de todas as possibilidades de criação de significações" (BAIRRÃO, 2003, p. 48).

É embasando-se em todas essas noções que se almeja, no presente estudo, entender de que forma a construção identitária, da imagem do eu e das perspectivas de vida dos jovens Xavante, viventes na experiência de trânsito entre dois universos espacialmente e culturalmente díspares, reflete-se nas apropriações e expressões de seus corpos-sujeito.

\section{MÉTODO}

A fim de cumprir com o objetivo proposto, foram realizadas entrevistas não estruturadas com três dos jovens situados na experiência de trânsito em questão e membros de suas famílias brancas, no intuito de compreender a inserção e especificidade simbólica dos entrevistados, em um quadro de encontros e desencontros interculturais. Todos os diálogos foram estabelecidos na cidade de Ribeirão Preto, ambiente urbano habitado pelos jovens.

Embasou-se a coleta e análise de dados na abordagem etnopsicanalítica, localizada na intersecção entre os saberes psicanalíticos e etnográficos. Essa confluência, antes de tudo, não deve ser entendida como de natureza interdisciplinar, mas configurando-se em uma pluridisciplinaridade diante da efetuação de uma dupla análise de determinados fatos, cada qual sob o prisma de ambos os campos do saber. Enuncia-se, deste modo, a relação de complementaridade entre esses dois sistemas de explicação (DEVEREUX, 1972).

Nessa perspectiva, enquanto a psicanálise, em sua capacidade de permitir uma escuta afinada do Outro enunciante, contribui com um olhar complexo sobre o outro, e também do Outro em nós mesmos, a antropologia auxilia no conhecimento desse em sua alteridade. Propõe-se, nesse caso, que o desconhecido se torne agente de investigação, desconhecido este que reside na alteridade e no que se refere aos processos inconscientes, manifestos na parte em falta em um discurso concreto da cadeia significante efetivamente proferida (BAIRRÃO, 2003; BAIRRÃO, 2015).

Considerando as noções acima descritas e entendendo que o significante em psicanálise é o que perfaz sentido, e não mera e exclusivamente algo atrelado 
à linguagem verbal (BAIRRÃO, 2011), sublinha-se que a atenção à expressão da corporalidade dos jovens em suas vivências de trânsito entre o urbano e seus locais de origem sustenta-se no exercício da etnopsicanálise em suas bases epistemológicas, antropológica e psicanalítica.

Müller (1976), citando Deetz (1967), dispõe conhecimentos da arqueologia para demonstrar a aplicabilidade de conceitos linguísticos a produções concretas humanas. Nessa perspectiva, artefatos, objetos ritualísticos e, no caso, produções no corpo, sendo resultado da atividade física e mental humana, comporiam parte da comunicação linguística, constituindo diferentes modos de expressão para um mesmo sistema (MÜLLER, 1976).

Partindo de semelhante perspectiva, sob outro prisma, Bairrão (2011), em anuência à leitura lacaniana de enunciação - podendo essa ser tida como verbal, corporal, estética, ou ainda de outras formas -, admite o figurativo, em si mesmo, constituindo-se como linguagem. Como já aqui descrito, o corpo é tido como abrigo do Outro, lugar onde se inscreve o significante, atuando como mediador e agente da produção de sentido. Situando-se no corpo, o Outro atua como simbólico, articulado ao sujeito agente. $\mathrm{O}$ inconsciente, esse que reside na parcela do enunciado em falta que revelaria o enunciante, diz e "diz-se" no corpo. Nesta perspectiva, aquilo que é ação, o que está além do verbal e pode ser etnografado (observado), pode ser também reconhecido e entendido como dito, logo, passível de escuta (BAIRRÃO, 2011; BAIRRÃO, 2015; BAIRRÃO, 2003). Citando Lacan (1986, p. 303):

Somos pois levados pela descoberta freudiana a escutar no discurso essa palavra que se manifesta através, ou mesmo apesar, do sujeito. Pelo seu corpo mesmo, o sujeito emite uma palavra que é, como tal, palavra da verdade, uma palavra que ele nem mesmo sabe que emite como significante. É que ele diz sempre mais do que quer dizer, sempre mais do que sabe dizer.

Atentando-se a essas noções e empregando a escuta flutuante, foram consideradas na análise relações e repetições dentre os relatos obtidos, bem como associações livres, conteúdos implícitos e até mesmo o que não foi efetivamente proferido, o que se refere ao inconsciente. Vale ressaltar que a tais dados não é atribuído sentido pelo pesquisador, mas sim pelos próprios participantes, ainda que o façam pelos ouvidos do primeiro. Isso se dá, pois o papel da psicanálise 
como embasamento metodológico não é o de fornecer explicações, mas de dar abrigo ao discurso do Outro, que por si só interpreta (BAIRRÃO, 2015).

É ponderosa a observação de que a sobressaliência do enfoque eleito para o presente artigo é resultado do efeito do campo no pesquisador. Aqui, não se trata apenas das repercussões do campo concreto, mas do inconsciente como campo, constituinte desse campo que possibilita e provoca as associações que conduzem a construção do estudo.

\section{RESULTADOS}

O contato com os conteúdos aqui discorridos se deu por meio de duas famílias residentes em Ribeirão Preto, cada qual abrigando dois irmãos Xavante, cujas trajetórias serão brevemente explanadas a fins de contextualização.

A primeira das famílias foi responsável por abrigar duas gerações de meninos Xavante: Canãbre (pai), que convivera com os brancos durante vinte anos, cumprindo com sua missão, formando-se em Enfermagem e retornando à aldeia de origem a fim de auxiliar seu povo, até vir a falecer pouco tempo depois por causas desconhecidas; e seus filhos Siwari e Canãbre, que passaram a residir em Ribeirão Preto desde que o segundo, mais novo, completara dois anos e meio. A história, destarte, produz seus ecos até a presente geração, em que os jovens filhos trilham o mesmo caminho do pai.

A questão do corpo já se apresenta relevante desde os princípios da formação da família: os índios mais velhos elegeram a mãe e avó branca dos Xavante supracitados, Vilma, entre as outras famílias candidatas à recepção de Canãbre (pai), por essa ser fisicamente parecida com eles. Fernandes (2015) discorre sobre o fato de que, ao pensar-se comparativamente nos corpos de brancos e Xavante, na visão desses últimos, não se trata de uma concepção genética ou biológica do corpo, mas de uma posição relacional dotada de fluidez, onde se está, e não se é. Ainda, tal posição relacional varia em conformidade com o grau de personitude que se confere ao outro, no caso, ao não índio (FERNANDES, 2015). A constituição corporal de Vilma, dessa forma, foi significativa na identificação e aproximação dos Xavante com ela, salientando a importância das marcas visuais no estabelecimento de relações com o outro para esse povo. Vilma foi, naquele momento, a partir de seus atributos físicos, associada à lógica Xavante - não sendo indígena, mas estando indígena. 
Nessa direção, aludiu-se a um estreitamento de vínculos entre tal família branca e os Xavante, havendo uma incorporação dessa em posições sociais desse povo. Os familiares ribeirão-pretanos parecem ter passado pelo processo de "captura" do outro descrito por Falleiros (2013). Trata-se de uma transformação do outro, capturado (há uma correspondência semântica na tradução dos verbos acolher, tomar e caçar para o Xavante: mrami, que pode ser interpretado no escopo da captura) em captor potencial, que passa a dotar das mesmas responsabilidades e atributos, quase encerrando um ciclo de transformação da presa em predador, predador da potência que reside no exterior, envolvendo o poder de dar e distribuir (FALLEIROS, 2013). Incorporados como membros da família Xavante, os não índios em questão passam a comprometer-se em trazer benefícios a esses, transmitindo esse ideal aos jovens por quem são responsáveis. Nesse sentido, os jovens abrigados por tal família expressam intencionar cumprir com seus objetivos primordiais no contato com o branco.

O mais velho deles, Siwari, havia retornado à aldeia temporariamente, tendo dado início à composição de sua família indígena: tivera, há pouco, sua segunda filha. Essa provocara ainda mais apego no jovem comparativamente à primeira filha, já que Siwari retornara à cidade pouco tempo após o nascimento da mais velha e não conseguira acompanhar de perto seu desenvolvimento. No momento presente, tem se aproximado, portanto, de seus semelhantes Xavante, de seus laços familiares originais.

Na ocasião da entrevista, havia retornado a Ribeirão Preto a fim de concluir seus estudos no ensino médio e iniciar formação no ensino superior, em Nutrição ou Educação Física. A escolha de tais cursos, além de consonantes com seus interesses pessoais, foi pensada considerando-se os benefícios que poderiam vir no cotidiano de suas aldeias de origem. Verificou-se, inclusive, uma renúncia a aspirações pessoais em prol de seu povo:

Siwari: É... ah, vamo falar assim, que essa vida [de jogador de futebol] não era pra... ter, né? Cê tá entendendo, né?

Canãbre: Porque se ele entrasse [no clube], com isso o que que ele ajudaria a aldeia?

S: É, é... Eu até pensava, assim, se eu for jogador eu até ajudava, mas é... ajudar com dinheiro é fácil, assim. Mas eu quero ajudar, tipo... ajudando lá, não ajudando longe. Isso que é o... 
Seu irmão Canãbre, por sua vez, trilhava no momento um caminho de retorno definitivo à aldeia. O jovem enfrentara algumas perturbações de sofrimento psíquico durante sua estadia no meio urbano, segundo ele atreladas a uma dificuldade em amoldar-se à rotina e às cobranças inerentes ao universo cotidiano e escolar ocidental. Tendo passado, em meio a essa experiência, por um importante processo inerente aos homens Xavante, composto por diversos rituais determinantes na transformação e entrada na vida adulta, Canãbre pôde entrar em contato mais profundo com sua ancestralidade. Tal processo simbolizou não apenas uma mudança em seu grupo de idade na aldeia, mas em sua autoimagem e concepção de ser: havia encontrado seu espírito a'uwe, havia se descoberto, de fato, um Xavante. Diante dessa nova perspectiva de si, seu retorno definitivo à aldeia de sua mãe resultou em uma melhora significativa em seu quadro.

A opção pelo retorno a suas raízes não significa, contudo, que Canãbre considere sua missão entre os brancos finalizada. O jovem expressou aspirar uma formação superior em Pedagogia, com o intuito de lecionar nas escolas existentes nas aldeias de seus familiares, direcionada à educação formal das crianças e jovens que lá habitam.

A escolha de Canãbre tem relação direta com a experiência escolar positiva vivenciada por ele e seu irmão. Eles frequentaram, durante a estadia em Ribeirão Preto, uma instituição de ensino de metodologia pedagógica Waldorf. Fernandes (2013) aponta para a importância de atentar-se ao papel desempenhado pelo aspecto corporal e da ideologia indígena referente aos sentidos em seus processos de apreensão do mundo, de aprendizagem. Salienta a relevância da dimensão do ouvir para os Xavante, referindo-se a uma sinonímia para as palavras "ouvir" e "aprender" para esse povo. Nesse sentido, por meio de abordagens metodológicas que ultrapassam o âmbito do "ver" e da escrita, a escola em questão parece trabalhar de maneira mais inclusiva e consonante com o modo de apreender o mundo indígena, o que a leva até a uma aproximação com o ensino propagado nas aldeias, aspecto presente na fala de Canãbre.

Para além da semelhança pedagógica por eles identificada, os irmãos em questão relatam ter tido um acolhimento positivo na instituição de ensino frequentada. Ao contrário dos Xavante de Rosa (2008) e de Oliveira (2010), que se depararam com um discurso etnocêntrico de inferioridade do outro defendido por alguns docentes e com incompreensão por parte de colegas a respeito de seus costumes e comportamentos, 
os irmãos expõem terem tido suas identidades respeitadas e exaltadas no contexto escolar, somando a uma convivência mista com os colegas brancos, isenta de grandes episódios de discriminação. Siwari, por exemplo, menciona como positiva a ocasião em que, no Dia do Índio, foi à escola ornamentado e pintado como de costume na aldeia, tendo recebido aprovação dos colegas e professores.

Todas essas minúcias brevemente discorridas acima parecem ser fundamentais na compreensão do movimento de forte autoafirmação como indígenas e perspectivas de futuro aliadas a seu povo, cada qual ao seu modo, realizado por Siwari e Canãbre.

O terceiro jovem abordado foi Serê, que reside hodiernamente em Ribeirão Preto, juntamente a seu irmão mais novo e à família branca que os abrigara. Serê veio a Ribeirão Preto pela primeira vez juntamente de seu avô paterno, quando tinha quatro anos de idade, por volta dos anos 2000. Conheceu sua família não indígena por intermédio de Vilma, em razão do Centro Espírita que os dois grupos familiares frequentam comumente. Diferentemente dos filhos e netos indígenas de Vilma, os quais ela expressou enfaticamente não serem de sua guarda formalmente, no caso de Serê um acordo de transferência de guarda chegou de fato a tramitar na Justiça. $O$ processo foi vagaroso, visto que os profissionais responsáveis alegavam que conceder a guarda do menino seria retirá-lo de suas origens. Decorridos dois meses, o avô e o tio de Serê intervieram no processo, argumentando a favor da transferência de guarda e conquistando a sentença favorável do juiz. O irmão mais novo veio pouco tempo depois, com a mesma idade em que viera o primeiro.

Serê relata que fora cotado para assumir a posição de liderança em sua aldeia desde pequeno, devido a sua fisionomia - sublinhando, nesse aspecto, mais uma vez a importância da construção e composição do corpo na sociedade Xavante - e atitude, descrevendo-se como um indivíduo "maduro" desde sempre. Sua decisão acerca de seu destino, todavia, vai na contramão dos planos que seus familiares e lideranças de seu povo idealizaram: quando terminou o ensino médio, fez cursos de eletricista residencial e técnico de segurança do trabalho, áreas ditas de seu interesse desde criança. Atualmente, trabalha em uma gráfica e intenciona seguir residindo em Ribeirão Preto. Tal decisão acabou por suscitar alguns conflitos, tendo o jovem declarado: 
Tipo assim, não faria muito sentido assim, de eu... Eu tá estudando, morar aqui e depois voltar pra assumir uma responsabilidade que, tipo, num... Vai ter muito sentido pra mim lá, entendeu? Aí essa parte eles num entende muito, não aceitam. Eles pensam, assim, que eu 'tô' deixando a tradição, assim, dos povo lá de... de lá mesmo. Aí, mas assim, na parte de mim num é... num é isso. Eu só, tipo... [vou] viver aqui, mas de outra forma ajudar eles lá. Eu quero ajudar, mas não, tipo, indo lá e ficando lá.

Não soube me dizer de imediato, no entanto, se já havia pensado em formas concretas de realizar essa pretensão. Os conflitos se estenderam para outros âmbitos, desde questões matrimoniais até o comparecimento do jovem em ocasiões rituais importantes em sua aldeia de origem, conflitantes com sua agenda de trabalho na cidade, entre outras incongruências.

A escolha de Serê por um caminho distinto do trilhado por seus primos enviados a Ribeirão Preto com o mesmo propósito pode estar atrelado a uma vivência também diversa no ambiente citadino. Como já descrito, a transferência de guarda de Serê e de seu irmão passou pelo âmbito formal judiciário, o que agrega um peso simbólico de maior significância nessa transição. Nesse quadro de concretude da guarda dos meninos, a família branca pareceu empenhar-se em menor medida em alimentar o elo com os membros da família de origem desses, produzindo ruídos na comunicação e afeição dos jovens em relação a seus familiares consanguíneos e a seu povo.

Ainda comparativamente, o jovem frequentou uma instituição de ensino distinta da de seus primos, em que enfrentou no princípio algumas dificuldades de convivência:

[...] no início mesmo me incomodava muito, porque eles... eles vinha se... os menino menor vinha queria pegar meu... meu cabelo com a mão, porque era liso, era diferente, era grandão. Aí eu não gostava muito não, quer dizer, mas... eu fui levando, fui criando as amizade, assim...

Nessas ocasiões, conta, chegava a agredir os colegas fisicamente, o que levava a diretora a chamar sua mãe branca na escola. Borges (2013), citando Orlandi (2004), alude a uma aceitação ou exclusão seletiva de determinados corpos, dependente dos contextos espaciais em que esses estão inseridos, reafirmando uma interconstitutividade entre corpo e ambiente na identificação do sujeito no discurso (BORGES, 2013). Tratando-se de um ambiente escolar de viés ocidental 
tradicional, desprovido de uma metodologia diferenciada e inclusiva, pode-se inferir uma contribuição desse para a conformidade de Serê aos padrões brancos e atenuação de suas marcas identitárias Xavante.

Como se pretende demonstrar, a dissimilitude entre as vivências expostas pelas personagens acima descritas se expressa para além de seus discursos, planos e visões de mundo. Ela é conspícua em suas construções de corporalidade, na forma com que externam as marcas identitárias corporais Xavante, seja salientando-as, modificando-as ou as suprimindo.

A temática já emergiu no primeiro contato realizado com Canãbre, juntamente a Vilma, sua avó branca. Logo no início do diálogo, ela apontou que o neto havia cortado o cabelo, que anteriormente se preservava muito comprido.

O cabelo constitui-se uma das principais marcas de identificação corporal dos Xavante, tendo um corte específico e característico e sendo raspado completamente apenas nas ocasiões de luto, em que se deixa todo o corpo nu, sem cor, indicando ausência de ornamentação. O corte de cabelo dos Xavante é uma forma de domesticar o pelo, tornando-o diferente daquele do animal (MÜLLER, 1976). É penteado e paramentado especificamente em eventos ritualísticos, não tendo o cabelo em si alguma propriedade especial, residindo sua importância simbólica no corte (CAMPOS, 2007).

Aprofundando-se sobre o assunto, Canãbre relata que sua avó materna indígena não chegou a conhecer o pai e por isso foi criada pelo irmão dele, esse que possuía um cabelo muito longo. Por isso, segundo ele, tanto sua mãe quanto ele e seu irmão haviam herdado essa característica, tal como a de serem "grandões", como ele. Canãbre conta que deixou o cabelo crescer a fim de assemelhar-se fisicamente ao avô. Quando expõe isso a outros membros da aldeia, é recebido com surpresa e questionamentos acerca do conhecimento do jovem sobre a história do ancestral, aos quais responde afirmativamente. Diz que os demais o incentivam a não cortar seu cabelo, mantê-lo comprido, a fim de deixá-lo igual ao do avô. No entanto todo o seu grupo de idade havia cortado os cabelos para participar da corrida final, da qual não participou por não estar na aldeia. A fim de buscar aproximação e identificação com seu grupo, Canãbre modificou seu corte em adequação ao restante dos jovens Xavante: "Aí cortei mesmo, pra não chegar com o cabelo grande e todo mundo de cabelo curto, e eu maior". 
Em todas as situações descritas, o modo como o jovem trata seu cabelo insere-se na lógica indígena, buscando aceitação e reconhecimento por seu povo, seja em conformidade às tradições Xavante, seja na identificação com seus ancestrais e demonstração dessa frente aos demais, ou na tentativa de misturar-se e assemelhar-se ao seu grupo de idade.

Canãbre e seu irmão, em todas as ocasiões de entrevista, preservavam seu corte consoante à característica específica de seu povo, declarando inclusive ser essa uma marca que permite diferenciar os Xavante de outros povos indígenas com facilidade. Siwari contou utilizá-lo para ilustrar aos amigos não indígenas sua especificidade, visando contrapor-se à imagem do índio genérico comumente difundida entre os brancos. Ambos os irmãos zombaram do fato de muitos questionarem se são Tupi-Guarani, família linguística indígena mais comumente conhecida. Também relatam já terem sido questionados se são chilenos ou indianos. Discorrendo sobre a temática, o mais velho explicita: "[...] Aí, por exemplo, quando a pessoa fala pra mim 'Ah, você é índio e tal..." eu sou, aí eu falo 'Sou Xavante'. Já falo na hora".

Assim como em Spaolonse (2006), delineiam-se contornos de uma expressão da corporalidade própria, que pode ser entendida, diante do contato com a sociedade envolvente, como representativa de uma almejada autenticidade étnica diante dessa em relação aos demais povos ameríndios, o que acaba por configurar-se politicamente vantajoso para esse povo. Considerando-se a noção concebida por Caiuby Novaes (1993), trata-se de assimilar a imagem gerada pela percepção do outro (branco) - neste caso, uma imagem carregada de estereótipos e generalizações - e direcionar suas formas de atuação (como na construção de seus corpos) de forma a corrigir essa imagem.

Ao deparar-se com Serê, por outro lado, pôde notar-se um corte de cabelo rente, muito diferente dos anteriormente observados. A temática emergiu brevemente durante seu relato. Ao retratar eventos de sua infância na cidade, menciona ter na época um corte de cabelo "estilo Chitãozinho e Xororó", como motejou. O corte mais congênere aos padrões brancos, segundo ele, teria sido feito há tempos, em um período tido pelo jovem como de maior adaptação e apreço pela vivência citadina. Em emendação ao tema concernente aos cabelos, o jovem declara:

Tipo assim, é... tava me adaptando, assim, gostando mais, mas não esquecendo o que eles me ensinava lá, assim, de tudo, assim... mesmo eu sendo pequeno eu sempre pensava lá, sabe? Aí... minha mãe sempre me perguntou, assim, se eu tinha saudade de lá e eu... eu falava que não. E isso já era de mim mesmo. 
Serê indica, por conseguinte, que, apesar de não esquecer suas origens e os ensinamentos dessas provindo, não se sente muito ligado afetivamente a elas, optando pela permanência no contexto em que se encontra. O corte de cabelo parece vir juntamente dessa percepção, de adaptação e assimilação do modo de viver ocidental.

Considerando-se Serê e seu irmão, ainda, a questão ganha dimensões mais complexas. Vilma conta que o cabelo de um deles, após três meses de permanência na cidade, mudou de liso, como característico dos Xavante, para crespo: "[...] mudou a textura total, parecia... pensa num cabelo de porco! Tamanha a negação de ser índio. Muito forte".

Alude-se, nesse caso, à noção já explorada na antropologia de aproximação entre transmutações corporais e apropriação de posições sociais, revelando uma lógica em que a natureza humana é delineada, modelada, fabricada pela cultura (VIVEIROS DE CASTRO, 1987).

Outra característica atribuída pelos meninos de Vilma como de grande relevância na identificação e no reconhecimento Xavante, contribuindo na diferenciação entre esse e os demais povos tradicionais, é a inserção de batoques auriculares. Tais adereços marcam passagem de determinado grupo de idade à condição de jovens para adultos, homens plenos. Tal processo mostrou-se relevante na trajetória de Canãbre, que na ocasião de seu primeiro diálogo para o estudo havia acabado de passar pelo ritual de furação de orelhas. A inserção dos batoques auriculares representa o poder de transformação característico da sociedade Xavante, visto que os adolescentes tornam-se, com ele, pessoas com papéis socialmente definidos na comunidade, logo se tornando nominadores, pais e com capacidade de participar da vida política da aldeia. O batoque inserido no lóbulo inferior é também uma forma de simbolizar processos ligados à compreensão e ao entendimento de mundo pelos quais o jovem passou, relacionando-se à função simbólica do "ouvir", associada à compreensão do que é dito, passado pelos mais velhos (FERNANDES, 2010; FERNANDES, 2015). A significação do ritual ganha força ainda maior no caso de Canãbre, este que fora permeado por processos extremamente complexos de compreensão, vindos de dois universos simbolicamente distintos, cuja fusão culminou na certeza de sua substância, sua essência, para a qual deveria direcionar todos os conhecimentos adquiridos em sua história de vida. 
No caso de Serê, por outro lado, os batoques tradicionais de madeira, durante sua vivência urbana, foram substituídos por alargadores de aço. Ele relata ter passado por vários dos rituais tradicionais concernentes a sua idade, tais como a luta com o'ió (ritual de resistência que marca a dualidade clânica estrutural da sociedade Xavante [TSI'RUI'A, 2012]), a corrida com toras de buriti (encenação ritual do roubo do fogo da onça pelos humanos, narrativa central dos povos Jê e Bororo, que marca a ideia de que a condição da existência coletiva indígena decorre da existência de capacidades transformadoras e de apropriação vinculadas à alteridade [VIANNA, 2008]) e o ritual em questão. Com o decorrer de sua vivência no meio urbano, todavia, declarou cansar-se dos brincos tradicionais. Seu irmão mais novo, ainda, teria deixado seus furos se fecharem, conforme comenta.

Considerando a simbologia dos batoques no sentido da representação dos processos de compreensão e entendimento de mundo passados pelos jovens que os recebem, vê-se na expressão da corporalidade de Serê uma associação à visão ocidental de mundo, a manutenção de um traço de identificação Xavante agora aliado a um objeto provindo do universo estético branco, às formas de compreensão desse universo. Em seu irmão mais novo, por sua vez, tido por Serê como ligado às suas raízes originais ainda em menor medida, observa-se a denegação dessas marcas: os furos se fecharam, a abertura para ouvir e incorporar as formas de entendimento Xavante se fechou.

Ainda, apesar de pretensões semelhantes para seus futuros, os irmãos Siwari e Canãbre também vivenciam e expressam suas experiências de formas distintas, particulares de suas formas de ser e estar no mundo. Essas formas de ser aparecem no discurso dos jovens também influenciadas por suas posições no espaço e no tempo. Em um de seus ensaios, Lopes da Silva (1983) defende a consideração dessas duas dimensões na construção da identidade Xavante, levando em conta um processo histórico de migrações constantes desse povo, impulsionado pela expansão da sociedade nacional (sic) sobre as áreas por eles sucessivamente ocupadas. Desse modo, a memória ancestral Xavante mostra-se permeada por noções de historicidade e territorialidade, engendrando um corpo de conhecimentos próprios que se tornam constitutivos do ser Xavante. Ao referir-se a essa dimensão histórica da territorialidade para esse povo, todavia, não se deve tratar de uma apropriação simbólica das referências territoriais em seu modo de ser e visão de mundo. Mais do que isso, em razão da transitoriedade espacial, trata-se 
de representações, ópticas e adoção de atributos pelos Xavante em relação a diversos grupos étnicos contatados durante esse percurso pelo espaço (LOPES DA SILVA, 1983). Essa noção, pensada diante da macro-história Xavante, pode ser aqui redimensionada relativamente aos microprocessos de trânsito vivenciados pelos jovens abordados. Os irmãos demonstram apresentar formas de atuação e um processo de adaptação a essas maneiras particulares de cada um, de acordo com o ambiente em que se encontram em sua trajetória.

Siwari expressa ter facilidade em inserir-se em ambos os contextos, característica corroborada por aqueles que convivem com ele: "É bem estranho, quando eu vou pra lá, tipo, eu viro assim... parece que eu sou uma... outra pessoa [...] é uma coisa boa, assim".

Canãbre, por sua vez, expressa necessitar de um tempo de adaptação quando em transição: "Eu chego... ai eu chego... e tenho que dar um tempo, ai"."

Pode-se observar, assim, certa interdependência entre as formas de ser e o meio atrelada a certa carga da dimensão temporal. Tais formas também repercutem em suas construções corporais e na maneira pela qual se apresentam ao mundo. A avó branca, Vilma, discorreu acerca da composição visual desempenhada por seus netos de acordo com suas formas de lidar com o meio: quando na cidade, Siwari performa sua estética de maneira "moderna", usando roupas "da moda", sendo descrito por Vilma como "vaidoso", enquanto na aldeia compõe o visual de forma a adequar-se ao contexto, não destoando dos demais. Já Canãbre, segundo o relato da matriarca, sempre se vestira de modo mais simples em contexto urbano, mantendo sua composição visual quase constante. Nesse sentido, acaba mostrando-se ligeiramente discrepante em relação aos demais, tanto no ambiente de origem quanto no urbano. O grau de conformidade da exterioridade do ser aos ambientes coaduna, dessarte, com os graus de facilidade em adaptar-se a esses anteriormente descritos, demonstrando Siwari ser mais habilidoso em "camuflar-se" rapidamente, se comparado ao irmão. Introduz-se aqui uma consciência mais clara do ser relacional Xavante, menos fixo em identidades formadas. Trata-se de uma lógica de construção da pessoa relacional e perspectiva, dependente da relação com o outro, tal como exposto por Fernandes (2015).

Como se pode averiguar, portanto, elementos estéticos da construção corporal indígena podem somar-se a sentidos coletivos e cosmológicos próprios, 
possibilitando novos olhares sobre esses e, desse modo, possibilitando uma escuta mais refinada dos processos de construções identitárias vivenciados pelos sujeitos indígenas. É ultrapassando essa significação trivial aparente que se abre a dimensão significante desses elementos corporais, que, por sua vez, permite a abertura a infindáveis sentidos na escuta do corpo. Considerando o corpo em sua dimensão simbólica como o abrigo do Outro, pode-se inferir que essa abertura significante constitui-se uma via à escuta do sujeito inconsciente. É por essa via, pela escuta do corpo como ação, que se pode observar nas minúcias do caso de Serê, por exemplo, que, não obstante seu discurso verbal em direção a uma autoafirmação Xavante e pretensão de contribuir com melhorias a seu povo, goza de uma posição de conformidade aos padrões brancos de ser, inserindo-se, dessarte, em uma forma de discurso mais "branca" dentro de um espectro relacional. Não se trata, aqui, de uma análise direcionada à negação de identidade provinda de um processo de "aculturação" - principalmente se considerarmos que suas modificações corporais acabam por seguir a lógica cosmológica Xavante, ainda que de maneira sutil -, mas de uma identificação do posicionamento do sujeito em seu próprio discurso.

A expressão da corporalidade dos jovens, como se espera ter evidenciado, pode estar também intrinsecamente relacionada à dimensão imaginária desse corpo, referente à identificação do sujeito com uma imagem e à transformação produzida pela assunção desta imagem nesse sujeito (LACAN, 1998). A depender do contexto e dos elementos que permearam suas vivências juntamente aos não índios, os jovens podem ter passado a produzir diferentes imagens de si, entremeadas ao desejo dos outros que pousam sobre eles seus olhares - ou pode-se dizer até, considerando a importância atribuída pelos Xavante à dimensão do ouvir, suas vozes, seus discursos - carregados de impressões e expectativas. Seria a partir dessa imagem formada - produto do embate entre os sistemas de valores envolvidos nas representações em questão (CAIUBY NOVAES, 1993) - que se produzem, desse modo, alterações nas imagens concretas, ou seja, nas marcas corporais produzidas pelos sujeitos indígenas. Escutar tais marcas configura-se, portanto, fonte de vastas percepções acerca desses.

Ainda dentro desse espírito de atenção a nuances e sutilezas que se inscrevem corporalmente no quadro de um diálogo, uma construção singular de um lugar de trânsito entre dois mundos, é também imprescindível considerar 
que os entrevistados não falam apenas por si: cumprem um mandato étnico de serem mediadores, informantes do mundo waradzu junto ao seu povo, tal como foi determinado na origem desse processo. Quaisquer que sejam as posições assumidas no espectro relacional com os brancos, a experiência de "urbanidade" vivenciada pelos jovens constitui-se uma forma de redarguição ao seu povo, a partir da via mais intensa e do ponto mais privilegiado de experimentação, na tentativa de acessar a perspectiva do branco: a inserção no locus de seu conhecimento (NUNES, 2010). A partir disso, o desejo que os habita pode ser visto além da perspectiva individual: os jovens movem-se e constroem-se por meio do Outro. A forma pela qual traçam suas trajetórias e delineiam seus corpos pode ser considerada, portanto, também uma reação e retorno às apostas e indagações originais que embasaram a estratégia étnica desses intercâmbios. Suas decisões aparentemente pessoais, noutro plano, transmitem também uma mensagem e fornecem respostas aos Xavante acerca de como interagir, reconfigurar-se e devir indígena em um contexto de inevitável fricção étnica e cultural.

O teor e os ecos de tais respostas para o povo indagador, no entanto, não são conhecidos até então por limitação do recorte empírico traçado por este estudo no presente momento (restrito à escuta dos personagens apresentados no ambiente citadino) e necessitam de maior aprofundamento.

De qualquer forma, os corpos dos jovens e as mudanças neles implementadas, algumas das quais aqui foram elencadas, podem ser entendidos também significantes, noutra escala, dos limites e das permeabilidades das fronteiras entre a territorialidade a'uwê e os espaços waradzu, sendo os jovens metonímias do povo Xavante, os representantes personificados destas fronteiras. Mediante paciente e acurada escuta etnopsicanalítica, há de se continuar a ouvir tais nuances, neste e provavelmente noutros casos de populações indígenas.

\section{CONSIDERAÇÕES FINAIS}

Pode-se constatar, por meio da escuta dos jovens para além do que efetivamente proferem, que suas apropriações identitárias, perspectivas de si e de seus próprios caminhos a serem trilhados produzem marcas visíveis em seus corpos, essas também passíveis de escuta. Marcas que dizem mais do que os olhos podem ver em um primeiro impacto, que ultrapassam significações puramente estéticas. 
Retomando as perspectivas teóricas em que se embasou o presente estudo, podemos inferir que atentar-se à expressão da corporalidade dos alvos do estudo é escutá-los como de fato se apresentam e representam em sua cultura. O corpo como se mostra é também ação, e é nele que reside o real do sujeito. A compreensão das minúcias acima descritas configura-se, portanto, imprescindível para o entendimento das experiências e visões de mundo dos jovens abordados e até mesmo de seu povo como um todo, quando a escuta é elevada ao plano do Outro Xavante.

Como afirmado por Nunes (2010), ao considerar-se o contato do indivíduo indígena com o meio urbano e os personagens que o permeiam, em oposição a uma generalização de "situação de urbanidade", tem-se que cada caso e suas especificidades envolvem modos e intensidades de relação com esses elementos. Nos processos aqui abordados, podem-se averiguar diferentes níveis de relação dos jovens com os componentes da sociedade envolvente - indivíduos, coletivos, modos de vida e perspectiva... -, tendo alguns incorporado - e corporificado - em maior ou menor medida os discursos predominantes nessa. Não obstante esses fenômenos de transformações e maleabilidade, cada qual ao seu modo, os jovens alcançaram formas de continuarem afirmando e, em alguns casos, performando suas identidades Xavante. Diante disso, evidencia-se no caso a ultrapassagem de concepções atidas à noção de aculturação dos povos ameríndios em contato com o urbano, respeitando suas sociocosmologias próprias.

A consideração dessas nuances, que dizem respeito à perspectiva particular de mundo do povo indígena em questão, sublinha-se também como relevante para o exercício de uma Psicologia crítica, comprometida com as problemáticas psicossociais contemporâneas, que englobe os sujeitos em suas especificidades socioculturais e mostre-se capaz de contribuir em suas lutas. Para tal, aprofundar-se em sutilezas como as aqui abordadas é imprescindível para uma atuação profissional diante dos povos ameríndios.

\section{REFERÊNCIAS}

BAIRRÃO, J. F. M. H. Etnografar com Psicanálise. Psicologias de um ponto de vista empírico. Cultures-Kairós, Les numéros, Anthropologie et psychanalyse: débats et pratiques, 2015. Disponível em: https://revues.mshparisnord.fr/cultureskairos/index.php?id=1197. Acesso em: 13 out. 2017. 
Substancialidade A'uwê no espelho Waradzu: escutar o corpo indígena Xavante em contexto de trânsito espacial e cultural

BAIRRÃO, J. F. M. H. Corpo e inconsciente. Revista Olhar, São Carlos, v. 8, p. 41-9, 2003.

BAIRRÃO, J. F. M. H. Nominação e agência sem palavras: o audível não verbal num transe de possessão. In: O movimento de um pensamento: ensaios em homenagem a Luiz Roberto Monzani. Curitiba: Editora CRV, 2011. p. 155-72.

BORGES, A. A. C. Da aldeia para a cidade: processos de identificação/subjetivação do índio Xavante na cidade de Barra do Garças/MT, alteridade irredutível? 2013. Dissertação (Mestrado em Linguística)- Instituto de Estudos da Linguagem da Universidade Estadual de Campinas, Campinas, SP, 2013.

CAIUBY NOVAES, S. Jogo de espelhos: imagens da representação de si através dos outros. São Paulo: Edusp, 1993.

CAMPOS, M. C. R. O corpo emana: elementos da plástica corporal Xavante. 2007. Dissertação (Mestrado em Artes)- Instituto de Artes, Universidade do Estado do Rio de Janeiro, Rio de Janeiro, RJ, 2007.

CUKIERT, M.; PRISZKULNIK, L. Considerações sobre eu e o corpo em Lacan - uma contribuição à questão do corpo em Psicanálise: Freud, Reich e Lacan. Estudos de Psicologia (Natal), v. 7, n. 1, p. 143-9, 2002. Disponível em: http://www.scielo.br/scielo. php?script=sci_arttext\&pid=S1413-294X2002000100014\&lng=en\&nrm=iso. Acesso em: 18 fev. 2020.

DEVEREUX, G. Ethnopsychanalyse complementariste. Tradução de Jolas, T. e Gobard, R. Paris: Flammarion, 1972.

FALLEIROS, G. L. J. Vir a ser e não ser gente através da participação etnográfica no Brasil Central. Universitas humanística, Bogotá, n. 75, p. 251-74, jan./jun, 2013. Disponível em: http://www.scielo.org.co/scielo.php?script=sci_arttext\&pid=S012048072013000100011\&lng=en\&nrm=iso. Acesso em:10 dez. 2019.

FERNANDES, E. R. Do Tsihuri ao Waradzu: o que as ideologias xavante de concepção, substância e formação da pessoa nos dizem sobre o estatuto ontológico do outro? Horizontes Antropológicos, Porto Alegre, v. 16, n. 34, p. 453-77, 2010. Disponível em: http://www.scielo.br/scielo.php?script=sci_arttext\&pid=S0104-71832010000200019\&ln $\mathrm{g}=\mathrm{en} \& \mathrm{nrm}=$ iso. Acesso em:15 out. 2017.

FERNANDES, E. R. Cosmologias indígenas, exterioridade e educação em contexto culturalmente diferenciado: um olhar a partir dos Xavante, MT. Tellus, Campo Grande, ano 10, n. 19, p. 97-110, jul./dez, 2013. Disponível em: http://tellus.ucdb.br/index.php/ tellus/article/view/219. Acesso em: 2 maio 2018. 
FERNANDES, E. R. Alimentação, corporalidade e doença: regimes de subjetivação do outro a partir de um estudo entre os índios Xavante (Mato Grosso, Brasil). Tessituras, Pelotas, v. 3, n. 2, p. 301-24, jul./dez., 2015. Disponível em: https://periodicos.ufpel.edu.br/ojs2/ index.php/tessituras/article/view/5922. Acesso em: 2 maio 2018.

ESTRATÉGIA Xavante. Direção de Belisário Franca. Rio de Janeiro: Giros, 2006. Disponível em: https://vimeo.com/216711158. Acesso em: 6 set. 2017.

GORDON, C. Os Xavante e suas circunstâncias. In: COIMBRA JR., C. E. A.; WELCH, J. R. (Org.). Antropologia e História Xavante em perspectiva. Rio de Janeiro: Museu do Índio - Funai, 2014.

HASHIGUTI, S. O corpo como materialidade do/no discurso. In: SEMINÁRIO DE ANÁLISE DO DISCURSO, 3., Porto Alegre, 2007. Anais [...]. Porto Alegre: SEAD, 2007. Disponível em: http://www.ufrgs.br/analisedodiscurso/anaisdosead/3SEAD/Simposios/SimoneHashiguti. pdf. Acesso em:18 fev. 2020.

LACAN, J. O Seminário Livro 1: os escritos técnicos de Freud. Rio de Janeiro: Jorge Zahar, 1986. [Texto original publicado em 1975].

LACAN, J. O estádio do espelho como formador da função do eu. In: LACAN, J. Escritos. Tradução de Vera Ribeiro. Rio de Janeiro: Jorge Zahar, 1998. p. 96-103. [Texto original publicado em 1966].

LOPES DA SILVA, A. A expressão mítica da vivência histórica: tempo e espaço na construção da identidade Xavante. Anuário Antropológico/82, 1983, p. 200-14. Acesso em: 5 ago. 2018.

MÜLLER, R. A. P. A pintura do corpo e os ornamentos Xavante: arte visual e comunicação social. 1976. Dissertação (Mestrado em Antropologia Social) - Instituto de Filosofia e Ciências Humanas, Universidade Estadual de Campinas, Campinas, SP, 1976.

NASIO, J. D. Cinco lições sobre a teoria de Jacques Lacan. Rio de Janeiro: Jorge Zahar, 1993.

NUNES, E. S. Aldeias urbanas ou cidades indígenas? Reflexões sobre índios e cidades. Espaço Ameríndio, Porto Alegre, v. 4, n. 1, p. 9-30, jan./jun. 2010. Disponível em: https:// seer.ufrgs.br/EspacoAmerindio/article/view/8289. Acesso em: 15 out. 2017.

OLIVEIRA, N. A. Xavantes, pioneiros e gaúchos: identidade e sociabilidade em Nova Xavantina/MT. 2010. Dissertação (Mestrado em Ciências Sociais) - Faculdade de Ciências Sociais, Universidade do Vale do Rio dos Sinos, São Leopoldo, RS, 2010.

ORLANDI, E. P. Textualização do corpo: a escritura de si. In: Cidade dos Sentidos. Campinas: Pontes, 2004. 
Substancialidade A'uwê no espelho Waradzu: escutar o corpo indígena Xavante em contexto de trânsito espacial e cultural

ROSA, L. M. Encontros e desencontros entre os a'uwê uptabi e os waradzu no espaço urbano de Barra do Garças-MT. 2008. Dissertação (Mestrado em História) - Faculdade de Ciências Humanas e Filosofia, Universidade Federal de Goiás, Goiânia, GO, 2008.

SOARES, J. Aspectos comuns da organização social Kaingang, Xavante e Bororo. Espaço Ameríndio, Porto Alegre, v. 2, n. 1, p. 44-67, jan./jun., 2008. Disponível em: https://seer. ufrgs.br/EspacoAmerindio/article/view/3114. Acesso em: 29 jan. 2020.

SPAOLONSE, M. B. Uma "tradição" em performance: corporalidade, expressividade e intercontextualidade num rito de iniciação social entre os Xavante de Sangradouro. 2006. Dissertação (Mestrado em Antropologia Social)- Centro de Filosofia e Ciências Humanas da Universidade Federal de Santa Catarina, Florianópolis, SC, 2006.

TORAL, A. A. "Xavantaço ou Funailaço?". Aconteceu Especial 17- Povos Indígenas no Brasil -85/86. São Paulo: Centro Ecumênico de Documentação e Informação, 1986. p. 344-47.

TSI'RUI'A, A. T. A sociedade Xavante e a educação: um olhar sobre a escola a partir da pedagogia Xavante. 2012. Dissertação (Mestrado em Educação) - Universidade Católica Dom Bosco, Campo Grande, MS, 2012.

VIANNA, F. L. B. Boleiros do cerrado - índios Xavantes e o futebol. São Paulo: FAPESP/ ISA/Annablume, 2008.

VIVEIROS DE CASTRO, E. A fabricação do corpo na sociedade Xinguana. In: OLIVEIRA FILHO, J. P. (Org.). Sociedades Indígenas e Indigenismo no Brasil. Rio de Janeiro: Editora Marco Zero, 1987.

\section{Sobre os autores:}

Maria Clara Campos: Graduanda em Psicologia pela Faculdade de Filosofia, Ciências e Letras de Ribeirão Preto (FFCLRP) da Universidade de São Paulo (USP) e pesquisadora de iniciação científica no Laboratório de Etnopsicologia da FFCLRP-USP. E-mail: campos.mclara.s@gmail.com, Orcid: http://orcid.org/0000-0001-6046-7209

José Francisco Miguel Henriques Bairrão: Doutor em Filosofia pela Universidade Estadual de Campinas (Unicamp) e livre-docente pela Universidade de São Paulo (USP). Pesquisador e docente de Psicologia Social no Departamento de Psicologia da Faculdade de Filosofia, Ciências e Letras de Ribeirão Preto da USP. Coordena o Laboratório de Etnopsicologia desta instituição, onde orienta e desenvolve pesquisas pautadas pelo interesse em não divorciar reflexão epistemológica 
(Epistemologia da Psicologia, Filosofia da Psicanálise) e pesquisa empírica (Psicologia da Cultura, Psicologia da Religião). E-mail: bairrao@usp.br, Orcid: http://orcid.org/0000-0001-6372-8873

Recebido em 24 de março de 2020.

Aprovado para publicação em 9 de junho de 2020. 